\title{
Enhancing online customer engagement in online room reservation: a structural modelling approach
}

\author{
Pisit Pipatphokakul ${ }^{1,{ }^{*}}$ and Watsida Boonyanmethaporn ${ }^{1}$ \\ ${ }^{1}$ National Institute of Development Administration, Bangkok, Thailand
}

\begin{abstract}
This research purposes to develop a structural equation model of enhancing online customer. The samples of this study consisted of 451 respondents who have purchased online room reservation via the website by convenient sampling method. The research instrument is a questionnaire. The data are analyzed by descriptive statistics and confirmatory factor analysis with AMOS. The result is the structural model of the confirmatory factor analysis of enhancing online customer engagement in online room reservation with empirical data Chi-Square/Df $=.954, \mathrm{CFI}=1.000, \mathrm{RMSEA}=.000, \mathrm{RMR}=.006$, and $\mathrm{TLI}=1$.
\end{abstract}

\section{Introduction}

In this era, the traveling business has shown a noticeable growth. Most people often spend a long time out of working hard to rest in their own places of interest. Online room reservation was the highest types of e-Commerce in the service business. For the information, it could be proved that digital/online shopping (E-commerce) is a significant trend to change the business pattern. Therefore, this paper will study an online room reservation context. In the past, online room reservation literature are found to mention important constructs, such as price, experience, website, booking intention, and trust.

However, this paper tries to link the key constructs of online hotel shopping to understand customer requirements and support to the service providers. This paper proposes reviewing the constructs (Online customer service, OCS; Online customer experience, OCX; Online room reservation, ORR; and Online customer engagement, OCE) and addressing a conceptual framework of online room reservation by literature review. The contribution to the online hotel shopping literature is including in two parts. First, there will bring new insights regarding constructs and dimensions of online room reservation, and second, the conceptual framework of online room reservation will be shown. Implementing what valued and engaged customers, as the framework can help service providers to better achieve their business. In the next session, the author introduces and presents the theoretical foundation, and framework for online room reservation.

\footnotetext{
*Corresponding author: pisit@impressionconsult.com
} 


\section{Literature Review}

\subsection{Online Customer Service (OCS)}

Online room reservation can make business growth for both hotels and online travel agencies with regarding OCS. OCS is one of the vital factors of the achievement of online industries. In addition, goods and services are relatively the same in any competitive market, the customer service can make a difference. Therefore, it is important to deliver OCS to customers, and to impress customers. OCS definition is a customer interaction to a service provider by human or non-human touch point. In e-commerce, OCS starts from entering the website, supporting the booking with problem-solving, and finishing transactions. The author concludes key dimensions of OCS are reliability [1], and capability (responsiveness, performance, and communication).

The relationship of OCS and other constructs, [2] investigated the factors affecting loyalty, there has been shown that the customer service had the greatest impact on customer loyalty (Due to loyalty is one of the dimensions of OCE). The enlarged connectivity of customers and the value of referrals and commendations [3], interaction between customer are the main parts of customer engagement [4]. This is consistent with the prior study. Therefore, the hypothesis is:

H1: Online Customer Service (OCS) affects Online Customer Engagement (OCE).

On the other hands, OCS also affects ORR because ORR is concerned with utilizing mobile devices, and websites. When customers make interaction with organizations, for example booking, reviewing, or repurchasing, efficiency is important. Also, OCS was concerned with customers usage of self-service instruments. The customer interactions (for example: questioning, booking, sharing, reviewing, and etc. in these moments, are computerized as well. Therefore, the hypothesis is:

H2: Online Customer Service (OCS) affects Online Room Reservation (ORR).

\subsection{Online Customer Experience (OCX)}

For delivering online customer service, the other construct that was greatly concerned is the online customer experience (OCX). There are two major characters of OCX including hedonics and utilization. Hedonics is an experience in the emotional/feeling mode and utilization mode is an experience in functional/reason mode which both of which are important to customer experience.

Therefore, the author defines definition of OCX as the perception of the customer to the online service provider. The dimensions of OCX will be defined for three dimensions including hedonics feature [5], utilization feature, and social interactions.

The relationship of OCX and other constructs, for social interaction, online customer experience affects the website. Also, customer connect to technology-mediated experiences should be made comfortable, more participated and simplified on multiple media [6]. In online customer experience, based on this context, the hypothesis has been formulated:

H3: Online Customer Experience (OCX) affects Online Room Reservation (ORR).

Considering the relationship of OCX and OCE, literature revealed that realizing how the OCX could affect the OCE was important in online shopping service contexts [7]. The sharing of experiences and opinions online are a dimension of engagement. The customer experience is the inner and instinctive feedback that customers had to make any interaction with a company. As a result, the customer can be perceived as engaging in cognitive and affective operation by the physical and features of a website, which as an outcome makes a delight of customer experience. Based on previous research, the formulation of the hypothesis is: 
H4: Online Customer Experience (OCX) affects Online Customer Engagement (OCE).

\subsection{Online Room reservation (ORR)}

ORR is an online service for reserving a room for a planned date and time. As room reservation is not the moment of staying in the hotel, a booking transaction would be careful decision in customer opinion. Typically, the room reservation is tracked by the approval. The author identified that the dimensions of ORR were defined for four dimensions including perceived ease-of-use [8], information quality, privacy risk, and website aesthetics [9].

The relationship of ORR and OCE, [10] proposed that perceived risks (dimension of ORR, associated with online shopping may affect customer attitudes towards online shopping, which determined online purchase intentions for services (dimension of OCE [11]. Based on previous research, this suggests the following hypothesis:

H5: Online Room reservation (ORR) affects Online Customer Engagement (OCE)

\subsection{Online Customer Engagement (OCE)}

Due to customer engagement is progressively supreme in today's extremely disruptive business [12], customer engagement is considered as a tactical authoritative in attractive business performance, including revenue growth [4], competitiveness [13] and profitability [14]. According to the literature review, the author summarized the four key dimensions of OCE are trust [15, 16], purchase intention [17], participation [18], and co creation [19].In this paper, OCE is results and benefits from other constructs. Therefore, studying online customer engagement (OCE) should yield more benefits to organizations and those businesses.

\subsection{The relationship among OCS, OCX, ORR, and OCE}

The relationship of OCS, OCX, ORR, and OCE can be found that the self-service technology has transformed service delivery structures as it allows customers to use a service through self-online connections of service providers' contribution [20]. Thus, altering connections is an interaction between room reservation service providers and customers. [21, 20] reported that customers' connections with online technological interfacing affect their behaviors and estimations. Base on previous research, it is proved that:

H6: Online Customer Service (OCS) affects Online Room Reservation (ORR) affects Online Customer Engagement (OCE)

[22] revealed that booked rooms were experience-related products whose value could be judged after purchase. For such goods and services, purchasers look for extra data from a variety of sources prior decide any purchase [23]. If online experiences through co-creation are the target [24], then online interaction is the mechanism that can initiate the target onward. Also, the technological platform was adapting the characteristic of customer experience. Based on previous research, the relationship between these three constructs can be expressed that:

H7: Online Customer Experience (OCX) affects Online Room Reservation (ORR) affects Online Customer Engagement (OCE). 


\subsection{Conceptual framework}

Based on the relevant information above, the relationship among constructs, the author can express the conceptual framework that was concerned with an online room reservation as Figure 1. - The conceptual framework of Online Room Reservation

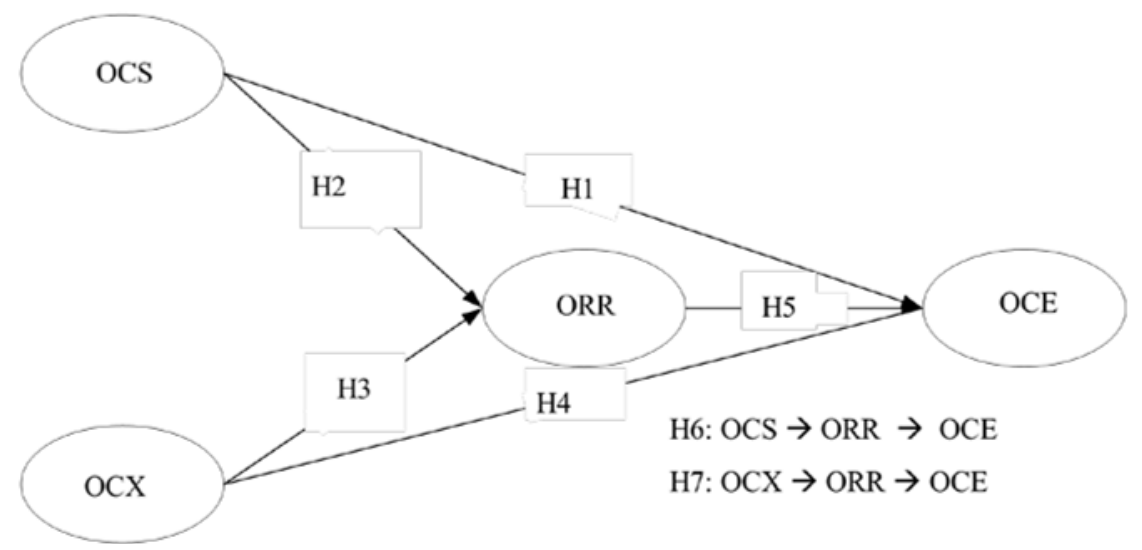

Fig. 1. Conceptual Framework.

The conceptual framework can be concluded into seven hypotheses. The seven hypotheses on online room reservation are shown as Figure 1. The seven hypotheses of the conceptual frame work among constructs can be concluded that OCS affects OCE, OCS affects ORR, OCX affects ORR, OCX affects OCE, ORR affects OCE, OCS affects ORR affects OCE, and OCX affects ORR affects OCE. The relationship of each construct on the conceptual framework can be supported online room reservation business for implementing what valued and engaged customers.

\section{Method and analysis}

The essential research method of this research and explained the fixed research procedures performed in the research. The process of this research is divided by two parts. The first part is research design including sampling techniques, collecting data, and questionnaire design.

The second part is collecting and analyzing data including screening data, testing normality, reliability, and validity, validating a second-order influential construct, and analyzing SEM. The section included detailed descriptions of research design, conceptual framework, research instrument, data collection, and analysis. Moreover, the applied approaches are concerned approach, and ethic.

\subsection{Measures}

The research design is used to fulfill objective [25]. This research uses the quantitative research method because the quantitative method can be applied to the research objective. The research instrument for the study was designed with items from validated scales for measuring online customer service, online customer experience, online room reservation website, and online customer engagement. Definitely, the respondent is a customer who experienced online purchasing/booking. 


\subsection{Samples}

In this research, the population is representative of customers who experienced online room reservations (for example booking by hotel website, online travel agency, hostel, lodgings, homestay, and etc.) with OTA and hotel website for accommodation. Sampling techniques are a portion of the population that is used to represent conclusions about the whole population [25]. The sample would be participants with online channels using convenient sampling techniques to gather information [26].

Each respondent is assigned a random code. Assemble quantitative data by utilizing an online questionnaire to collect data from a customer who experienced an online room reservation via OTA, hotel, and other room reservation websites [27,28]. The reason for selecting a convenient sampling technique is the participations who experienced online room reservation via OTA, hotel, and other room reservation websites.

\subsection{Analysis}

A quantitative method agrees with the researcher to study of the relations among constructs. The data can be utilized to explore cause and effect relations. This research analyzed collected data by employing the structural equation modeling (SEM) technique using the samples by indicating the size as the number function of the parameters. The aspect of the design is used to develop and confirm tools to measure constructs in the proposed model, including items and the constructs of online room reservations. Then, the hypotheses proposed are studied with structural equation modeling (SEM). This research objective is to develop a model of enhancing online customer engagement in online room reservation.

\section{Results}

H1: Online customer service (OCS) influences on online customer engagement (OCE)

Hypothesis 1 predicted that online customer service significantly influences online customer engagement. The structural model as presented in Figure 2 showed the path coefficient $(\beta)$ of the direct variable OCS on OCE. In this study, OCS is in the form of reliability and capability, while OCE represents repurchasing \& word-of-mouth, and sharing. As illustrated in Table 1, Hypothesis 1 is accepted, OCS depicted an insignificant related to OCE $(\beta=.415, \mathrm{t}=7.845, \mathrm{p}<0.001)$.

$\mathrm{H} 2$ : Online customer service (OCS) influences on online room reservation website (ORR)

Hypothesis 2 expects online customer service (OCS) significantly influence online room reservation website (ORR). The structural model presented in Figure 2 estimates the path coefficient of online customer service (OCS) on online room reservation website (ORR). The outcomes exposed that online room reservation website is positively related to ORR $(\beta=.307, \mathrm{t}=11.081, \mathrm{p}<0.001)$, validating Hypothesis 2 . Thus, online customer service is likely to influence online room reservation website.

H3: Online customer experience (OCX) influences on online room reservation website (ORR)

Hypothesis 3 proposed that online customer experience (OCX) is positively interrelated to online room reservation website (ORR). The model presented in Figure 2 shows the path estimates of online customer experience on online room reservation website. The results, as shown in Table1, demonstrated that online customer experience is positively and significantly related to online room reservation website, supporting Hypothesis $3(\beta=.063$, $\mathrm{t}=5.162, \mathrm{p}<0.001)$. The result signifies that online customer experience is likely to online room reservation website. 
H4: Online customer experience (OCX) influences on online customer engagement (OCE)

Further, online customer experience is positively related to online customer engagement. The path of online customer experience, and online customer engagement, estimates as illustrates in Figure 2 and Table 1. Results showed that online customer experience is positively and significantly related to online customer engagement, supporting Hypothesis $4(\beta=.147, \mathrm{t}=6.547, \mathrm{p}<0.001)$. There is signifying that the more provision from online customer experience is available, online customer engagement will likely be higher.

H5: Online room reservation website (ORR) influences online customer engagement (OCE)

Hypothesis 5 proposed that online room reservation website has a positive influence on online customer engagement. Hypothesis 5 is validated as presented in Figure 2 and Table $1(\beta=.063, \mathrm{t}=3.017, \mathrm{p}<0.01)$ confirming that ORR has a positive and significant influence on OCE. The findings show that the higher level of ORR, the better OCE will likely be customer engaging.

H6: Online customer service (OCS) influences on Online customer engagement (OCE), mediated by Online room reservation website (ORR)

As for Hypothesis 6, ORR is a mediator with the relationship between online customer service and online customer engagement. The results from the bootstrapping and the Sobel test exposed that the mediating effect of ORR between online customer service and online customer engagement is significant (standardized indirect effect $=.019, \mathrm{CI}=.007$ (LL) to $.046(\mathrm{UL}), \mathrm{z}=2.8273, \mathrm{p}<0.01)$. Mediation analysis explains that if the path estimate from the independent variable to the dependent variable is significant when the mediator is included in the model, then partial mediation is justified. As shown in Table 1, online customer service is significantly related to online room reservation website (Hypothesis 2). Consequently, Hypothesis 6 is accepted by the partial mediation effect of ORR.

H7: Online customer experience (OCX) influences on Online customer engagement (OCE), mediated by Online room reservation website (ORR)

The structural model

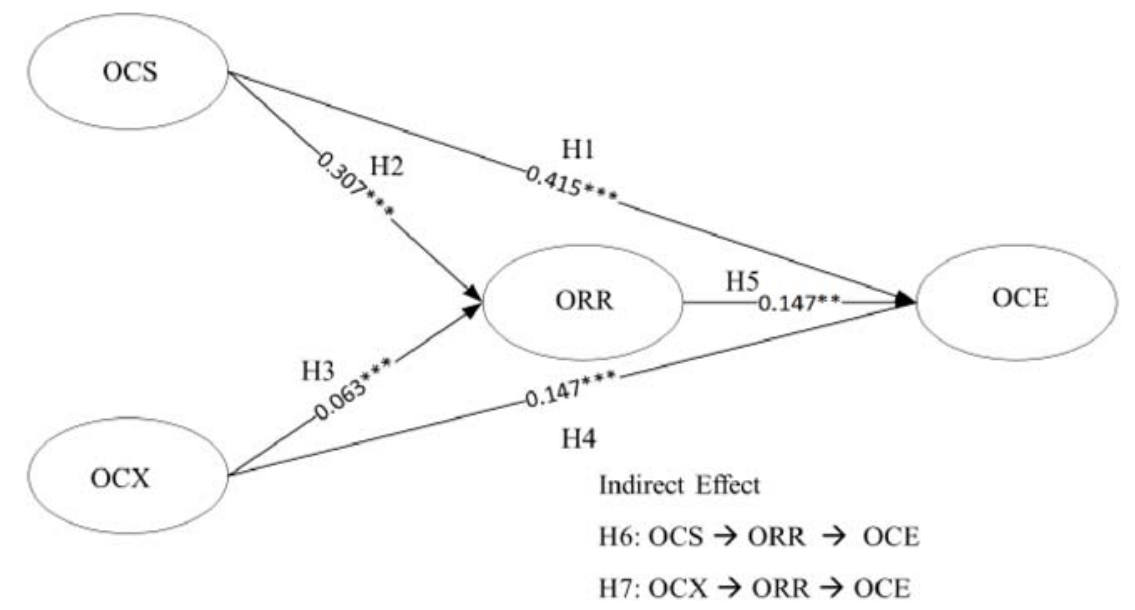

Note: $\mathrm{N}=451 ;{ }^{*} \mathrm{p}<0.05,{ }^{*} \mathrm{p}<0.01,{ }^{* *} \mathrm{p}<0.001$

Fig. 2. The structural model of the research.

Hypothesis 7 proposes that ORR is hypothesized to mediate the relationship between online customer experience and online customer engagement. The results from the 
bootstrapping and the Sobel test exposed that the mediating effect of ORR between online customer experience and online customer engagement is significant (standardized indirect effect $=.004, \mathrm{CI}=.001(\mathrm{LL})$ to $.007(\mathrm{UL}), \mathrm{z}=2.5426, \mathrm{p}<0.05)$. As shown in Table 1, online customer experience is significantly related to online room reservation website (Hypothesis 3). Consequently, Hypothesis 7 is supported by the partial mediation effect of ORR.

Table 1. Summary results of Hypothesis testing for $\mathrm{H} 1$ to $\mathrm{H} 7$.

\begin{tabular}{|c|c|c|c|c|c|}
\hline Hypothesis & $\boldsymbol{\beta}$ & b & SE & t-value & Results \\
\hline $\mathrm{H} 1:$ OCS $\rightarrow$ OCE & .415 & .542 & .069 & $7.845 * * *$ & Accepted \\
\hline H2: OCS $\rightarrow$ ORR & .307 & .657 & .059 & $11.081 * * *$ & Accepted \\
\hline H3: OCX $\rightarrow$ ORR & .063 & .067 & .013 & $5.162 * * *$ & Accepted \\
\hline $\mathrm{H} 4: \mathrm{OCX} \rightarrow \mathrm{OCE}$ & .147 & .095 & .014 & $6.547 * * *$ & Accepted \\
\hline H5: ORR $\rightarrow$ OCE & .063 & .038 & .013 & $3.017 * *$ & Accepted \\
\hline $\begin{array}{l}\text { Mediating effects } \\
\text { of OCE }\end{array}$ & \multirow{2}{*}{$\begin{array}{c}\text { Standard } \\
\text { indirect } \\
\text { effects }\end{array}$} & \multicolumn{2}{|c|}{$\begin{array}{c}\text { Bootstrapping } \\
95 \% \text { CIs }\end{array}$} & $\begin{array}{l}\text { Sobel test } \\
\text { Z-values }\end{array}$ & Results \\
\hline & & LL CIs & UL CIs & & \\
\hline $\begin{aligned} \text { H6: OCS } \rightarrow \text { ORR } & \\
& \rightarrow \text { OCE }\end{aligned}$ & .019 & .007 & 046 & $2.8273^{* *}$ & Accepted \\
\hline $\begin{aligned} \text { H7: } & \text { OCX } \rightarrow \text { ORR } \\
& \rightarrow \text { OCE }\end{aligned}$ & .004 & .001 & .007 & $2.5426^{*}$ & Accepted \\
\hline
\end{tabular}

Note: $\mathrm{n}=451 ; * \mathrm{p}<0.05 ; * * \mathrm{p}<0.01 ; * * * \mathrm{p}<0.001$ (two-tailed), $\beta=$ standardized path coefficient, $\mathrm{b}=$ unstandardized coefficient, $\mathrm{SE}=$ standard error, OCS $=$ online customer service, $\mathrm{OCX}=$ online customer experience, $\mathrm{ORR}=$ online room reservation website, $\mathrm{OCE}$ $=$ online customer engagement, bootstrapping with 2000 re samples, CIs $=$ Confident intervals, $\mathrm{LL}=$ lower bound level, $\mathrm{UL}=$ upper bound level

Table 2. Summary of Direct effect, Indirect effect, and Total effect.

\begin{tabular}{|c|c|c|c|c|c|c|}
\hline \multirow{3}{*}{$\begin{array}{c}\text { Exogenous } \\
\text { variables }\end{array}$} & \multicolumn{6}{|c|}{ Endogenous variables } \\
\hline & \multicolumn{3}{|c|}{ ORR } & \multicolumn{3}{|c|}{ OCE } \\
\hline & $\mathbf{D E}$ & IE & TE & DE & IE & TE \\
\hline OCS & $.657 * * *$ & - & .657 & $.542 * * *$ & $.025 * *$ & .567 \\
\hline OCX & $.067 * * *$ & - & .067 & $.095 * * *$ & $.003 * *$ & .098 \\
\hline ORR & - & - & - & $.038^{* *}$ & - & .038 \\
\hline $\mathrm{SMC}(\mathrm{R} 2)$ & \multicolumn{3}{|c|}{ ORR $=.114$} & \multicolumn{3}{|c|}{$\mathrm{OCE}=.268$} \\
\hline \multicolumn{7}{|c|}{ Model fit statistics } \\
\hline \multicolumn{7}{|c|}{$\chi 2 / \mathrm{Df}=.954, \mathrm{CFI}=1.000, \mathrm{RMSEA}=.000, \mathrm{RMR}=.006, \mathrm{TLI}=1.000$} \\
\hline
\end{tabular}

Note: $\mathrm{DE}=$ Direct effect, $\mathrm{IE}=$ Indirect effect, $\mathrm{TE}=$ Total effect, $\mathrm{SMC}=$ Square multiple correlation,

OCS $=$ online customer service, OCX $=$ online customer experience, ORR $=$ online room reservation website, $\mathrm{OCE}=$ online customer engagement, bootstrapping with 2000 resamples, $\mathrm{CIs}=$ Confident intervals, $\mathrm{LL}=$ lower bound level, $\mathrm{UL}=$ upper bound level

Conclusion, the proposed hypotheses model generated a good fit to experiential data $(\chi 2 / \mathrm{Df}=.954, \mathrm{CFI}=1.000, \mathrm{RMSEA}=.000, \mathrm{RMR}=.006$, and TLI $=1.000)$. Overall results as presented in Table 2 for the hypothesized structural model testing show that the experiential data supports all seven proposed hypotheses, $\mathrm{H} 1-\mathrm{H} 7$ demonstrate the significant direct effect relationship of OCS, OCX, ORR, and OCE.

Regarding the total effects on OCE as shown in Table2, H1 is the strongest effect on OCE significantly, followed by H6: online customer service influences on online customer engagement mediated by online room reservation website (OCS $\rightarrow$ ORR $\rightarrow$ OCE). The results of square multiple correlations in Table 2, these three focal constructs jointly explained $26.8 \%$ of the variance in online customer engagement. The indirect relationship 
in $\mathrm{H} 6$ and $\mathrm{H} 7$ are supported by the value of standardized indirect effect and Z-values resulting from bootstrapping and the Sobel tests, similarly.

\section{Discussion and Conclusion}

\subsection{Findings}

This study initiates the structural equation model of enhancing online customer engagement. The model includes four constructs namely; 1) online customer service, 2) online customer experience, 3) online room reservation website, and 4) online customer engagement. The structural equation model of enhancing online customer engagement shows that online customer service influences online customer engagement and online room reservation website while online customer experience influences online room reservation website and online customer engagement. Additionally, the online room reservation website influences online customer engagement. The model can be described that online customer service influences online customer engagement mediated online room reservation website and online customer experience influences online customer engagement mediated online room reservation website.

\subsection{Managerial implications}

According to the fit model of this research, the model of enhancing online customer engagement can be described in which online customer engagement which manager can be increased by improving online customer service, online customer experience, and online room reservation website as the following contents.

As delivering online customer service is a fundamental of every business that could start and go on. In the fit model of the research, online customer service only influences online room reservation website, this result can be described that company and manager could increase online customer engagement significantly with improving online customer service by mediating online room reservation website. So, the company and manager could deliver online customer service through the room reservation website.

The fit model of this research can be confirmed that online customer experience directly both impact online room reservation website and online customer engagement. This study has correspondingly emphasized the vital impact of customer experience on an online room reservation journey. The dimensions of online customer experience can be separated into two parts, including emotional and utilitarian features. The finding of model analysis of online customer experience, the emotional feature is dramatically higher impact than utilitarian feature.

According to the fit model of the present research, an online room reservation website is a mediator that both affected by online customer service and online customer experience, and influences on online customer engagement significantly. This understanding can help the company and manager to achieve their online customer engagement target basically.

Online customer engagement is the result of this present research model. From the fit model, there can be proved that the highest influence on online customer engagement is an online room reservation website so the company and manager can firstly improve on their websites. The results will make online customer engagement be better. 


\subsection{Theoretical implications}

An academic implication of this study importantly provides several implications to the existing figure of literature. First, the study is exceptional in that develops a theoretical model exploring the relationship between online customer service, online customer experience, online room reservation website, and online customer engagement concurrently in the model in which online customer services, and online customer experience is referred to as independent variables, with customer engagement as a subsequent variable to validate the mediating effect of online room reservation website. The structural equation model (SEM) analysis recommends that the model is valid to empirical provision for all seven hypotheses. This topic presents academic implication intuition regarding online customer engagement and its significant relationship with online customer service, online customer experience, and online room reservation website. As theory concerned, the researcher develops the model empirically contributes to the online tourism research to develop the thoughtful of the fundamental relationship of these four key constructs in an online room

\subsection{Limitations and future research avenues}

The present research analyses the relationship among four constructs and presents a theoretical framework and model with various theoretical implications and practical recommendations presented above, the limitations in this research should be recognized for future researches, which the study analyses the relationship among four constructs which on the online room reservation website. Nevertheless, the growth of social media usage in this era, the next research should analyse the relation among construct compare with online room reservation websites and social media. Also, comparing loading between the website and social media influences online customer engagement. The result will guide the company and manager to develop their online platform strategy to achieve online customer engagement targets.

\section{References}

1. J. Wang et al., The Service Industries Journal 37(5-6) (2017)

2. K. Mohammadi et al., Journal of Basic and Applied Scientific Research 2(4) (2012)

3. B. Libai et al., Journal of Service Research 13(3) (2010)

4. V. Kumar et al., Journal of Service Research 13(3) (2010)

5. A. Bilgihan et al., International Journal of Quality and Service Sciences 8(1) (2016)

6. U. Gretzel, T. Jamal, Tourism Analysis 14(4) (2009)

7. G. McLean, A. Wilson, Computers in Human Behavior 60 (2016)

8. A. Tanti, D. Buhalis, Information Technology \& Tourism 17(1) (2017)

9. X. Xu, The effects of website quality on customer satisfaction, use intention, and purchase intention: A comparison among three types of booking channels (2017)

10. S. Wani, S. Malik, International Journal of Marketing \& Business Communication 2(4) (2013)

11. R. Thakur, Journal of Retailing and Consumer Services 41 (2018)

12. E. Jaakkola, M. Alexander, Journal of Service Research 17(3) (2014)

13. M. Pitukhina, International Journal of Ecology \& Development 32(3) (2017)

14. P. Verhoef et al., Journal of Retailing 85(1) (2009) 
15. D. Ushakov, L. Kharchenko, International Journal of Ecological Economics and Statistics 38(2) (2017)

16. V. Potdar et al., Information Technology \& People 31(2) (2018)

17. E. Dudukalov, Contemporary Economics 10(4) (2016).

18. P. Harrigan et al., Tourism Management 59 (2017)

19. A. Prívara, M. Př́varová, Sustainability 11(20) (2019)

20. M. Meuter et al., Journal of Marketing 64(3) (2000)

21. D. Ushakov et al., International Journal of Ecological Economics and Statistics 38(4) (2017)

22. A. Cezar, H. Ögüt, International Journal of Contemporary Hospitality Management 28(2) (2016)

23. A. Papathanassis, F. Knolle, Tourism Management 32(2) (2011)

24. B. Neuhofer, An Exploration of the technology enhanced tourist experience (Bournemouth University, 2014)

25. D. Cooper, P. Schindler, Business Research Methods (The McGraw- Hill Companies, 2014)

26. A. Př́vara, Geografický časopis 71(2) (2019)

27. E. Popkova et al., European Research Studies Journal 20(1) (2017)

28. T. Podolskaya et al., E3S Web of Conferences 244 (2021) 